NASA Technical Memorandum 104364

AIAA-91-2135

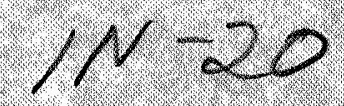

19132

920

\title{
Experimental and Analytical Studies of Flow Through a Ventral and Axial Exhaust Nozzle System for STOVL Aircraft
}

Barbara S. Esker

Lewis Research Center

Cleveland, Ohio

and

James R. DeBonis

Sverdrup Technology, Inc.

Lewis Research Center Group

Brook Park, Ohio

Prepared for the

27th Joint Propulsion Conference cosponsored by the AIAA, SAE, ASME, and ASEE

Sacramento, California, June 24-27, 1991 
EXPERIMENTAL AND ANALYTICAL STUDIES OF FLOW THROUGH A VENTRAL AND AXIAL EXHAUST NOZZLE SYSTEM FOR STOVL AIRCRAFT

\author{
Barbara S. Esker \\ NASA Lewis Research Center \\ Cleveland, Ohio 44135
}

\author{
James R. DeBonis* \\ Sverdrup Technology, Inc. \\ Lewis Research Center Group \\ Brook Park, Ohio 44142
}

\section{SUMMARY}

Flow through a combined ventral and axial exhaust nozzle system was studied experimentally and analytically. The work is part of an ongoing propulsion technology effort at NASA Lewis Research Center (NASA Lewis) for short takeoff, vertical landing (STOVL) aircraft. The experimental investigation was done on the NASA Lewis Powered Lift Facility. The experiment consisted of performance testing over a range of tailpipe pressure ratios from 1 to 3.2 and flow visualization. The analytical investigation consisted of modeling the same configuration and solving for the flow using the PARC3D computational fluid dynamics program. The comparison of experimental and analytical results was very good. The ventral nozzle performance coefficients obtained from both the experimental and analytical studies agreed within 1.2 percent. The net horizontal thrust of the nozzle system contained a significant reverse thrust component created by the flow overturning in the ventral duct. This component resulted in a low net horizontal thrust coefficient. The experimental and analytical studies showed very good agreement in the internal flow patterns.

\section{INTRODUCTION}

Supersonic Short Take-off, Vertical Landing (SSTOVL) aircraft are proposed for future military application. These aircraft would utilize a single propulsion system to provide power for lift and hover as well as for supersonic horizontal flight. Currently, NASA Lewis Research Center (NASA Lewis) plays an important role in developing key propulsion technologies for the development of SSTOVL aircraft. The active programs to develop these technologies include offtake ducts and valves, integrated aircraftpropulsion controls, nozzles, and hot gas ingestion in ground effects.

Many propulsion configurations have been studied. A sample, from a US/UK ASTOVL study (ref. 1), is shown in figure 1. These studies have narrowed the possible configurations to a propulsion system that has remote vertical lift in jet-borne flight and mixed flow for wing-borne flight. A propulsion configuration of this nature would likely require a ventral nozzle for pitch control and trim. The ventral nozzle would be located in the lower fuselage of the aircraft. Because it would have to be fully contained in the fuselage, the ventral nozzle would be positioned closely against the engine tailpipe. When pitch control and trim are required, a valve would open the ventral duct to the engine tailpipe to direct a jet of mixed exhaust gases downward. For hover, the main exhaust nozzle would be closed and other lift producing devices would be activated. During transition between these two conditions, 
horizontal wing-borne flight and vertical jet-borne flight or hover, the mixed exhaust gases will be directed out both the main axial nozzle and the ventral nozzle.

A rectangular ventral nozzle and a conical axial nozzle were tested on a one-third scale model tailpipe. This configuration was assembled from existing hardware and is shown in figure $2(a)$. The ventral nozzle is shown dïrected upward for operational convenience. This configuration was used to study the flow physics of air exhausting simultaneously out of both nozzles. The total exit area of the nozzles resulted in a Mach number in the tailpipe of approximately 0.6 at a tailpipe pressure ratio of 3.0. This Mach number is higher than current engine practice $(\sim 0.3)$. However, it was felt that the essential flow features and behavior would exist and provide valid comparison between analytical and experimental results. The nozzles were sized to give approximately a $60 / 40$ flow split out the ventral and axial exhaust nozzles, respectively. This configuration was then modeled analytically

(fig. 2(b)) and the flow computed using the PARC 3D computational fluid dynamics code (ref. 2). This code solves the threedimensional, Reynold's-averaged Navier-Stokes equations and includes an algebraic turbulence model. A block version of the PARC3D code was used to simplify construction of the grid and to reduce the computer memory requirements for a fairly complex geometry.

The overall objectives of the work were to: (1) establish the thrust and flow performance characteristics of the ventral and axial exhaust nozzle system over a tailpipe total pressure ratio range of 1 to 3.2 , (2) understand the internal flow patterns and physics of the system, and

(3) evaluate the performance of the chosen CFD code to predict the experimental performance. The results described in this paper consist of specific comparisons between experimental and analytical results in the form of performance graphs and flow visualization images.

\section{APPARATUS AND INSTRUMENTATION}

Test Stand

The tailpipe, ventral nozzle, and axial nozzle configuration was mounted on the NASA Lewis Research Center Powered Lift Facility (PLF) as shown in figure 3 . This outdoor test stand can measure three forces (axial, vertical, and side) and three moments (pitch, roll, and yaw). A net resultant force and resultant angle were calculated from the measured axial and vertical forces. The capability of the stand to accurately measure the forces and compute the effective flow angle was established using a standard nozzle and precision pipe elbows to produce a force at a known angle. The PLF is capable of measuring forces with an accuracy of 1 percent and the calculated flow angle was found to be equal to the known flow angle to within $\pm 1^{\circ}$. Airflow measurements for the PLF were made with an ASME nozzle in the facility air supply line and were found to be accurate to within 0.5 percent.

\section{Model}

Figure 4 is a schematic of the tailpipe assembly with both the ventral and axial exhaust nozzles. This assembly consisted of a 
reducer from the 24 in. diameter facility piping to the 13.5 in. diameter tailpipe, several flow conditioners, and the approximately one-third full scale model tailpipe representative of military tailpipes in diameter. The assembly had a modular construction to allow for testing a variety of ventral nozzle configurations.

The ventral nozzle is rectangular and convergent with an exit area of 75 in. ${ }^{2}$ ( 60 percent of the total exit area). A practical STOVL aircraft design would

require that the ventral nozzle be wholly contained within the fuselage and as such would be close against the engine tailpipe. In order to simulate this close coupling as well as a worst case condition for total pressure loss of the flow turning into the ventral duct (ref. 3), the ventral duct was designed to form a square leading edge at the intersection with the tailpipe. This hardware is the same as the ventral nozzle configuration with a blocked axial nozzle (ref. 4).

The axial exhaust nozzle is conical and convergent with an exit area of 57 in.2. This area was approximately:40 percent of the total exit area.

The hardware also included a thin flow visualization plate which could be mounted on the centerline of the tailpipe across the opening into the ventral duct. This plate extended downstream of the ventral opening. The plate was used only for flow visualization testing and was not installed for the performance testing of the configuration.

\section{Instrumentation and Data Processing}

The number and location of the total pressure instrumentation for the model is shown in figure 4 . Wall static pressure measurements were made in the tailpipe and in the ventral duct. Tailpipe total pressure measurements were made at station 5 which is located in the tailpipe upstream of the ventral opening. These pressures were measured by 16 tubes ( 4 rakes of 4 tubes) in the mainstream flow and 20 tubes ( 4 rakes of 5 tubes) in the boundary layer flow. The 36 pressures were then weighted by area to calculate an average total pressure for that station. Ventral duct total pressure measurements were made at station 6 immediately upstream of the ventral nozzle. The pressure was measured by 24 tubes which were weighted by area to calculate an average total pressure. Axial nozzle total pressure measurements were made immediately upstream of the nozzle (station 7) using the same distribution of tubes as used at station 5. For the pitot-pressure survey of the ventral nozzle exit plane (station 6B), a fivetip total pressure rake was traversed in four spanwise locations to survey the entire exit area. Data from the facility instrumentation included pressures and temperatures which were used to calculate the total air flow through the system.

\section{TESTING PROCEDURE}

Performance Tests

Steady-state performance testing of the combined ventral and 
axial exhaust nozzle system consisted of flow and thrust measurements over a range of tailpipe pressure ratios (PR5) up to 3.2 . An upper limit of 3.2 for the tailpipe pressure ratio was chosen due to facility limitations and concerns about excessive noise generation.

\section{Ventral Nozzle Exit Plane Survey}

Pitot-pressure surveys were made at the ventral nozzle exit (station 6B). For this part of the test, the five-tip rake was traversed across a plane 0.25 in. downstream of the ventral nozzle exit. This was done at four locations along the width of the nozzle to obtain data for the entire exit area. The data obtained were then used to create a contour plot of the pitot pressure levels at the exit.

\section{Flow Visualization}

Paint streak flow visualization was used to obtain a qualitative image of the flow through the nozzle system. This technique involved placing dabs of a thick oily paint on the thin flow visualization plate (fig. 4) which was mounted on the tailpipe centerline across the ventral opening. The paint was also applied to the walls of the ventral duct and nozzle. The air supply to the system was started quickly, held at approximately a tailpipe pressure ratio of 2.0 for $1 \mathrm{~min}$, and then quickly shut off. The paint streaked along the streamlines of the flow and provided a clear image of the flow patterns.

\section{COMPUTATIONAL FLUID DYNAMICS}

\section{PARC 3D Code}

The ventral and axial exhaust nozzle system was studied analytically using the full Navier-Stokes code, PARC3D. PARC solves the Reynolds-averaged Navier-Stokes equations. It employs the BeamWarming approximate factorization algorithm. Turbulence was simulated using the Baldwin-Lomax turbulence model for wall bounded flows (ref. 5). The PARC3D code was run on the Cray $\mathrm{Y}$-MP computer at the NASA Ames Research Center Numerical Aerodynamic Simulation (NAS) facility.

The blocked version (i.e., the computational domain was divided into several simple blocks) of the code was used for the combined nozzle analysis. This approach eased grid generation of complex shapes. Each grid block was solved separately and a tri-linear interpolation scheme transferred. data between adjacent block boundaries (ref. 2). Grid blocking also reduced the amount of computer memory required, since only the data for the block currently being solved is held in memory.

\section{Computational Grid}

The grid representing the geometry, shown in figure 5 , was made up of three blocks: the cylindrical tailpipe, the rectangular ventral nozzle, and the conical axial nozzle. Each block is a simple shape, which was easily generated. The tailpipe and the ventral nozzle grids were taken from the analysis of Smith and 
McArdle (ref. 6). The tailpipe grid was modified to better join with the axial nozzle. The axial nozzle grid was generated using the INGRID3D code (ref. 7). A total of 684,063 nodal points were used (tailpipe: 101 by 51 by 51 , ventral duct and nozzle: 51 by 51 by 101 , axial nozzle: 61 by 51 by 51). Since a plane of symmetry is present in the experimental hardware, only one half of the nozzle system was modeled.

\section{Boundary Conditions}

Because it was not desired to model the external flow, a boundary condition was needed at the nozzle exits. However, the flow here was transonic. To properly impose a boundary condition which would not adversely affect the interior flow field, a fictitious diverging section was added to each nozzle. The flow expanded to supersonic speeds and the conditions at the fictitious boundary were extrapolated. This technique avoided placing a boundary condition at the actual exit plane of each nozzle. This had been done previously with good results (ref. 6).

The tailpipe and axial nozzle were modeled using 0-grids. Problems calculating metrics (coordinate transformation derivatives) occur in the center of the grid where the grid lines become coincident. A pole boundary condition was created where the flow properties on this boundary were calculated by averaging the values along the adjacent grid lines.

\section{RESULTS AND DISCUSSION}

The results of the experimental and analytical studies compared well. Significant per formance parameters for the combined ventral and axial exhaust nozzle system are given in Table I. The graphics generated from the analytical results were done using the PLOT3D program (ref. 8).

\section{Turning Losses}

The turning loss for the ventral nozzle was defined as the loss in average total pressure of the flow as it moved from the tailpipe into the ventral duct. The turning losses are plotted against tailpipe pressure ratios in figure 6 . At a tailpipe pressure ratio of 2.874 , the flow showed an 18 percent turning loss experimentally and a 10.5 percent turning loss analytically. The large turning loss measured experimentally was due to severe flow angles in the ventral duct which affected the total pressure measurement obtained at station 6 . The flow angles were apparent in the flow visualization which will be discussed in detail.

The same ventral nozzle configuration with the axial nozzle blocked was tested and reported in reference 4. In this case, the turning loss from the tailpipe into the ventral duct was 5.5 percent and was caused by flow separation off the front wall of the ventral duct. This flow separation occurred because of the square corner at the opening into the ventral duct. The larger turning losses in the current ventral and axial exhaust nozzle configuration implied that the separation off the front wall of the ventral duct was larger. The larger separation region was caused by the presence of the throughflow out the axial nozzle. This separation will be discussed later in more detail. 


\section{Discharge Coefficient}

Discharge coefficients for both the ventral and axial exhaust nozzles were calculated as the actual flow out of the nozzle divided by the ideal flow out of that nozzle based on conditions upstream at station 5 . These results are shown in figure 7 . The ventral nozzle discharge coefficient was measured to be 0.8366 at a tailpipe pressure ratio (PR5) of 2.874. The computational analysis agreed with the experimental results to within 1 percent. The low value of ventral nozzle discharge coefficient was a result of the turning losses in the flow as it turned from the tailpipe to the ventral duct.

The axial nozzle discharge coefficient was measured experimentally to be 0.9405 which is typical for conical nozzles (ref. 9). However, the discharge coefficient calculated analytically was nearly 6 percent higher the experimental value. The high analytical value for discharge coefficient could be caused by a slight false increase in total pressure in the downstream section of the tailpipe. This increase in total pressure is created by the artificial dissipation model near the pole boundary condition. This issue is under further review.

\section{Thrust Coefficient}

Thrust coefficients (fig. 8) were calculated for both the ventral and axial exhaust nozzles. The ventral nozzle thrust coefficient can be considered to be the net vertical thrust coefficient for the nozzle system because the axial nozzle did not generate vertical thrust. This coefficient was calculated as the net vertical thrust from the nozzle system divided by the ideal vertical thrust from the ventral nozzle. A thrust coefficient value of 0.9279 was obtained experimentally at a tailpipe pressure ratio of 2.874 and this value agreed with the computational result within 1.2 percent. The low value resulted directly from the turning loss from the tailpipe into the ventral duct.

Unlike the ventral:nozzle thrust coefficient, the axial nozzle thrust coefficient cannot be considered to be the net horizontal thrust coefficient for the nozzle system. This is because the ventral nozzle was found to create a significant horizontal thrust opposite to the horizontal thrust created by the axial nozzle. The negative horizontal thrust created by the ventral nozzle resulted from the loss in the flow average total pressure caused by flow separation off the front wall of the ventral duct. The separation created a low pressure region which then caused the ventral flow to overturn and exit the nozzle at an angle toward the inlet to the tailpipe. This flow angle out of the ventral nozzle generated a horizontal thrust in a direction opposite (or negative) to the thrust created by the axial nozzle. The net horizontal thrust was the sum of the thrust created by the axial nozzle and the negative horizontal thrust created by the ventral nozzle. The net horizontal thrust coefficient was calculated as the net horizontal thrust from the nozzle system divided by the ideal horizontal thrust from the axial nozzle. The experimental value for the net horizontal thrust coefficient was 0.7452 . This value was 4.5 percent lower than the value obtained analytically. The net horizontal thrust coefficient obtained analytically was affected by the region of slightly high total pressure created by the artificial 
dissipation model in the PARC3D code which was discussed earlier.

\section{Boundary Layer Flow Visualization}

The particle traces in the boundary layer, as predicted by the PARC3D code, are shown in figure 9. These traces indicated that the majority of the lowmomentum boundary layer flow was drawn off by the ventral nozzle. This boundary layer flow was then entrained in three-dimensional vortices in the ventral duct. One of these vortices is shown in figure 9. Another vortex would exist in the other symmetric half of the duct. Figure 10 shows the total pressure contours along the plane of symmetry. These contours indicate a sharp total pressure gradient (indicative of the sharp velocity gradient of the boundary layer) in the tailpipe upstream of the ventral nozzle. This figure also shows that the total pressure gradient was minimal on the ventral side of the tailpipe immediately downstream of the ventral duct. This result implies that the boundary layer (total pressure gradient) started to reform along the ventral nozzle side of the tailpipe.

\section{Flow Visualization on Plane of symmetry}

Figures $11(\mathrm{a})$ and (b) show the results of the experimental flow visualization test and the particle traces on the plane of symmetry, respectively. Both the paint streaks and the traces illustrated that the airflow from the ventral nozzle side of the tailpipe exited through the ventral nozzle. A stagnation point existed on the ventral nozzle side of the tailpipe just downstream of the ventral duct opening. Immediately upstream of this point, the tail- pipe flow reversed direction to exit through the ventral nozzle. Downstream of this point, the flow exited through the axial nozzle. The flow from the side of the tailpipe opposite of the ventral nozzle diffused downstream of the ventral duct. Specifically, a portion of the air from this side flowed diagonally to the ventral nozzle side of the tailpipe downstream of the ventral duct. This flow then dispersed as it moved down the tailpipe. This effect is shown in figure 10 and resulted in a distorted pressure distribution at station 7 . The total pressure is approximately 4.7 percent lower in the half of the tailpipe opposite of the ventral nozzle.

Figure 10 also shows the region of slightly high total pressure along the pole boundary condition in the downstream portion of the tailpipe. As mentioned earlier, this region of pressure created by the artificial dissipation model had an affect on the analytical calculation of both the axial nozzle discharge coefficient and the net horizontal thrust coefficient.

Velocity Profile at station 5

Figure 12 gives, for station 5 , the analytical velocity profiles along the ventral and opposite halves of the diameter of the tailpipe. These figures also show the experimental average velocity for the ventral and opposite halves of the tailpipe. Experimentally, the difference in average velocity between the two halves is approximately 6 percent. This difference in average velocity (and velocity profile) between the two halves is related to the total pressure gradients of the ventral and opposite halves of the tailpipe. The total pressure contours are shown in figure 10. At 
station 5, the region of total pressure gradient on the ventral side of the tailpipe is thicker than the region of total pressure gradient on the opposite side of the tailpipe. These two effects, the difference in velocity and the difference in total pressure gradient between the two halves of the duct, are due to the upstream influence of the ventral nozzle.

\section{Flow Visualization on Ventral Duct Walls}

Front wall. - Figure 13(a) shows the paint streak flow visualization on the front wall of the ventral duct and figure 13(b) shows the particle traces. Although only one of the symmetric halves of the ventral and axial exhaust nozzle system was modeled by the CFD, the second half was created as a mirror image of the first for the purposes of comparison with the experimental flow visualization. The vortices on the front wall of the ventral duct and nozzle are seen very clearly in both figures and the comparison between the experimental and computational analysis was excellent. These vortices were three dimensional (figs. 13(a) and 14(b) show two dimensions) and formed as a result of the flow separation off the front wall of the ventral duct. After the air turned the corner into the ventral duct it immediately started to flow toward the centerline and into the vortex. A stagnation line existed approximately half way down on the ventral nozzle surface. Upstream of this line the flow was pulled strongly into the vortex; that is, the air flowed horizontally in toward the center of the ventral duct, and then down farther into the duct and into the vortex. Downstream of the stagnation line, the flow was also drawn toward the center of the duct then exited the nozzle.

Side walls. - The flow visualization on the side walls of the ventral duct (figs. 14(a) and (b)) showed that the air overturned, that is, flowed diagonally back toward the inlet to the tailpipe. This flow in the ventral duct was pulled at approximately a $60^{\circ}$ angle. The overturning of the airflow in the ventral duct was caused by the low pressure region of the vortex. The air flow was overturned as it exited the ventral nozzle which created the horizontal thrust negative to the horizontal thrust created by the flow out the axial nozzle. The overturning of the airflow also contributed to the threedimensionality of the vortices. Again, the experimental and the computational results compared very well. The computational result (fig. 14(b)) indicated a stagnation point approximately half way down on the side wall of the ventral nozzle. Upstream of this point, the air flowed down into the duct as it was entrained into the vortex. Downstream of the stagnation point, the flow exited the nozzle nearly perpendicular to the nozzle exit plane. This stagnation point in the side wall image (fig. $14(\mathrm{~b})$ ) corresponded to an end view of the direct inboard flow seen in the front ventral duct wall image (figs. 13(a) and (b)). This result indicated that the vortices are highly three-dimensional.

Back wall. - The visualization of the flow immediately along the back wall of ventral duct is shown in figures $15(\mathrm{a})$ and (b). Both the experimental and computational analyses indicated that this flow was not drawn into the vortices at the front of the duct, rather, it 
exited straight out the ventral nozzle.

\section{Pressure at Ventral Nozzle Exit Plane}

Figure 16 shows a comparison of the experimental contour plot of the pitot pressures and the analytical contour plot of the total pressures at the ventral nozzle exit plane. These results compared well. Both contour plots indicated that a region of low pressure existed in approximately half of the ventral nozzle. This low pressure region was indicative of the vortex which has been shown in previous figures. In both the experimental and the analytical studies, the minimum pressure at the ventral nozzle exit plane was approximately 52 percent of the normalized upstream total pressure of $44.088 \mathrm{psia}$. The low pressure region of the vortex caused the flow to exit the nozzle diagonally toward the inlet to the tailpipe.

\section{CONCLUDING REMARKS}

A combined ventral and axial exhaust nozzle configuration was tested at steady-s.tate pressure ratios up to 3.2 . Although the Mach number in the tailpipe was higher than in conventional engine practice, the configuration exhibited the essential flow features and provided an opportunity to compare analytical and experimental results.

The results of the PARC3D computational fluid dynamics code compared well to the experimental results. The analytical studies indicated that the boundary layer was nearly completely drawn off by the ventral nozzle. The boundary layer started to reform on the ventral duct side of the tailpipe downstream of the ventral duct. On the opposite side of the tailpipe downstream of the ventral duct, the flow dispersed to be distorted at the entrance to the axial nozzle.

The studies also indicated that the flow separated from the front wall of the ventral duct and large vortices were formed in this region. This behavior resulted in a low pressure region which caused the ventral nozzle air flow to overturn back toward the inlet to the tailpipe and create a significant rearward thrust component. This reverse thrust component adversely affected the horizontal thrust of the axial nozzle and resulted in a low net horizontal thrust coefficient for the nozzle system.

Several variables of the ventral and axial exhaust nozzle system are being considered for future research:

1. Lower tailpipe Mach number at the ventral duct inlet

2. Ratio of the exit area of the ventral nozzle to the exit area of the axial nozzle more representative of potential configurations.

\section{REFERENCES}

1. Levine, $J$. and Inglis, M., "US/UK Advanced Short Takeoff and Vertical Landing Program," AIAA 89-2039, July 1989.

2. Cooper, G. and Sirbaugh, J., "The PARC Distinction: A Practical Flow Simulator," AIAA paper 90-2002, July 1990. 
3. Esker, B.S. and McArdle, J.G., "Performance Characteristics of a One-Third-Scale, Vectorable Ventral Nozzle for STOVL Aircraft," NASA TM-103120, July 1990 .

4. McArdle, J.G. and Smith, C.F., "Experimental and Analytical Study of Close-Coupled Ventral Nozzles for ASTOVL Aircraft," NASA TM-103170, Aug. 1990.

5. Baldwin, B.S. and Lomax, H., "Thin-Layer Approximation and Algebraic Turbulence Model for Separated Turbulent Flows," AIAA Paper 78-257, Jan. 1978.

6. Smith, C.F. and McArdle, J.G., "Analysis of Internal Flow in a Ventral Nozzle for STOVL Aircraft," AIAA Paper 90-1899, July 1990. (See also NASA TM-103123, July 1990.)

7. Soni, B.K., "Two- and ThreeDimensional Grid Generation for Internal Flow Applications of Computational Fluid Dynamics," AIAA Paper 85-1526, July 1985 .

8. Walatka, P.P., et. al. "PLOT3D Users Manual," NASA TM-101067, 1990

9. Stitt, Leonard, "Exhaust Nozzles for Propulsion Systems With Emphasis on Supersonic Cruise Aircraft," NASA RP1235, May 1990. 
TABLE I. - PERFORMANCE PARAMETERS FOR VENTRAL AND AXIAL NOZZLE SYSTEM

\begin{tabular}{|c|c|c|}
\hline & $\begin{array}{l}\text { Experimental } \\
\text { results }\end{array}$ & $\begin{array}{l}\text { Analytical } \\
\text { results }\end{array}$ \\
\hline $\begin{array}{l}\text { Ratio of upstream tailpipe } \\
\text { total to ambient pressure, PR5 }\end{array}$ & 2.874 & 2.874 \\
\hline $\begin{array}{l}\text { Ratio of ventral duct total to } \\
\text { ambient pressure, PR6 }\end{array}$ & 2.325 & 2.572 \\
\hline $\begin{array}{l}\text { Ratio of downstream tailpipe } \\
\text { total to ambient pressure, PR7 }\end{array}$ & 2.825 & 2.953 \\
\hline $\begin{array}{l}\text { Ventral nozzle discharge } \\
\text { coefficient based on station } 5\end{array}$ & .8366 & .8408 \\
\hline $\begin{array}{l}\text { Axial nozzle discharge } \\
\text { coefficient based on station } 5\end{array}$ & .9405 & .9937 \\
\hline $\begin{array}{l}\text { Net vertical thrust } \\
\text { coefficient based on station } 5\end{array}$ & .9279 & .9391 \\
\hline $\begin{array}{l}\text { Net horizontal thrust } \\
\text { coefficient based on station } 5\end{array}$ & .7452 & .7789 \\
\hline $\begin{array}{l}\text { Ventral nozzle flow rate } \\
\text { corrected to station } 5\end{array}$ & 21.25 & 21.667 \\
\hline $\begin{array}{l}\text { Axial nozzle flow rate } \\
\text { corrected to station } 5\end{array}$ & 18.38 & 19.405 \\
\hline $\begin{array}{l}\text { System resultant thrust } \\
\text { corrected to station } 5\end{array}$ & 959.7 & 1018.5 \\
\hline $\begin{array}{l}\text { Net vertical thrust corrected } \\
\text { to station } 5\end{array}$ & 781.3 & 804.2 \\
\hline $\begin{array}{l}\text { Net horizontal thrust } \\
\text { corrected to station } 5\end{array}$ & 539.3 & 597.4 \\
\hline
\end{tabular}




\section{ORIGINAL PAGE \\ BLACK AND WHITE PHOTOGRAPH}

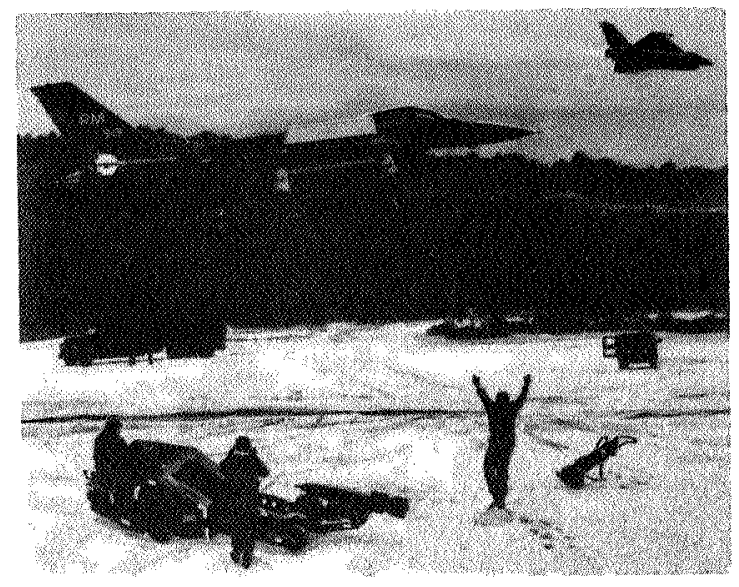

(a) Ejector augmentor.

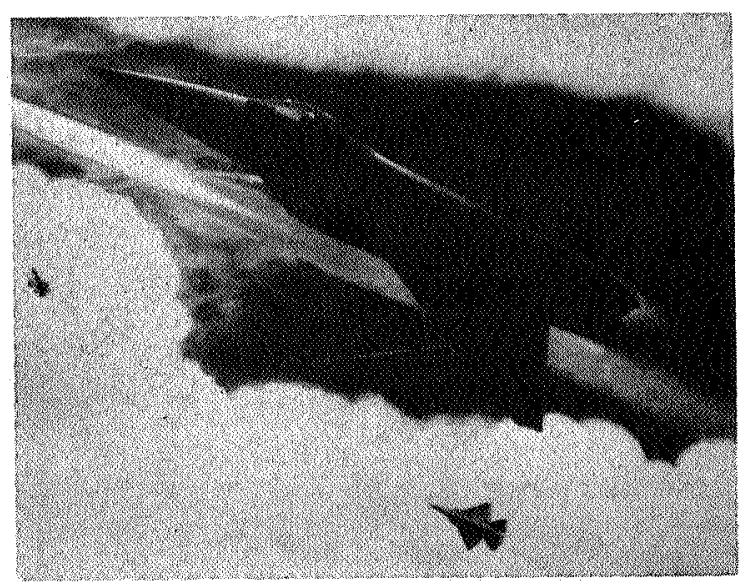

(c) Mixed-flow vectored thrust.

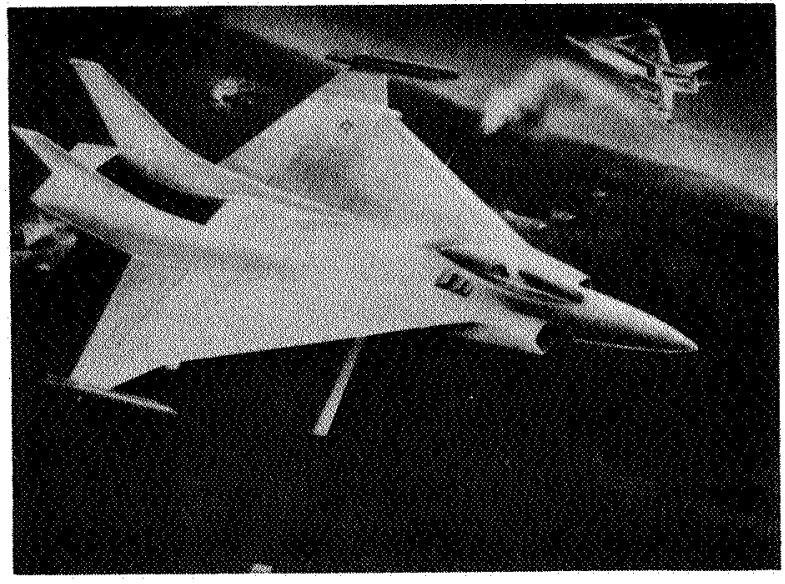

(b) Remote augmented lift system.

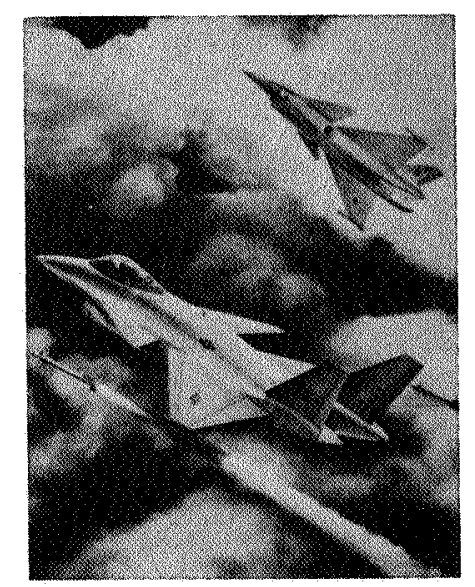

(d) Hybrid tandem fan.

Figure 1-Artists' conceptions of possible configurations for future supersonic STOVL aircraft. 


\section{ORIGINAL PAGE \\ BLACK AND WHITE PHOTOGRAPH}

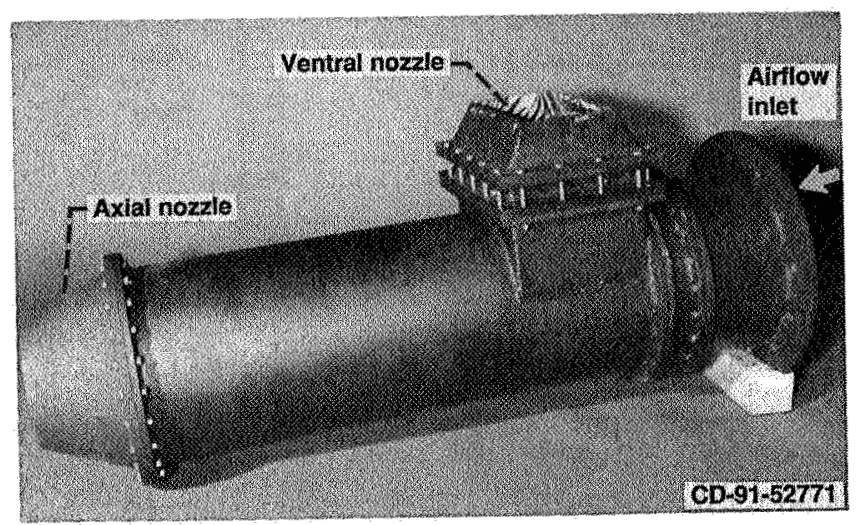

(a) Experimental hardware.

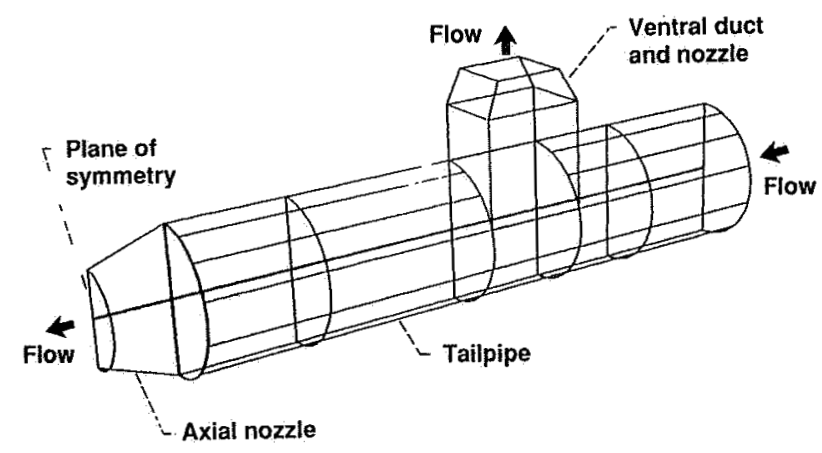

(b) Analytical "wire mesh" grid. Only one-half is used for CFD. For clarity. many of the grid lines are not shown.

Figure 2.-Ventral and axial nozzle configuration.

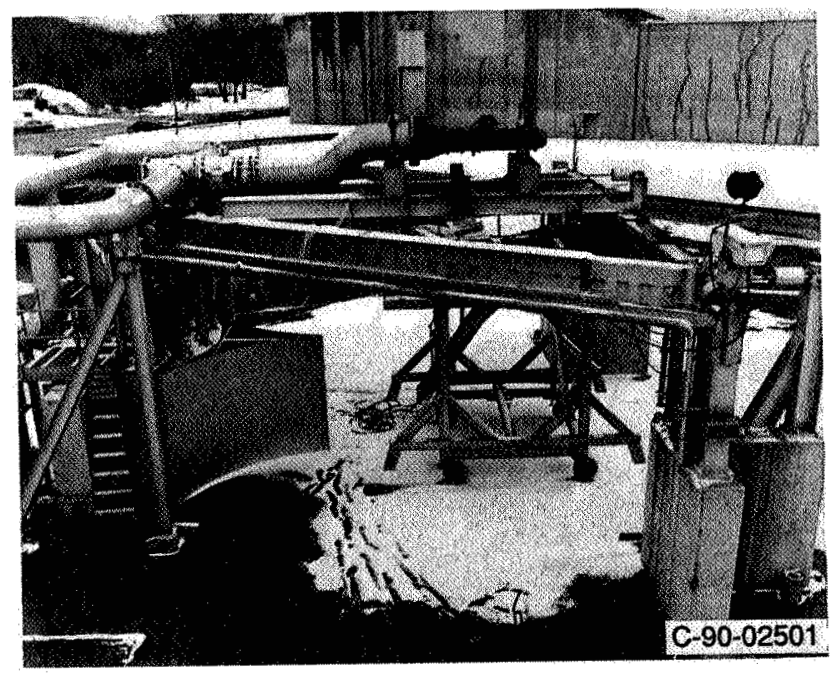

Figure 3.-- Powered lift facility with ventral and axial nozzle configuration. 


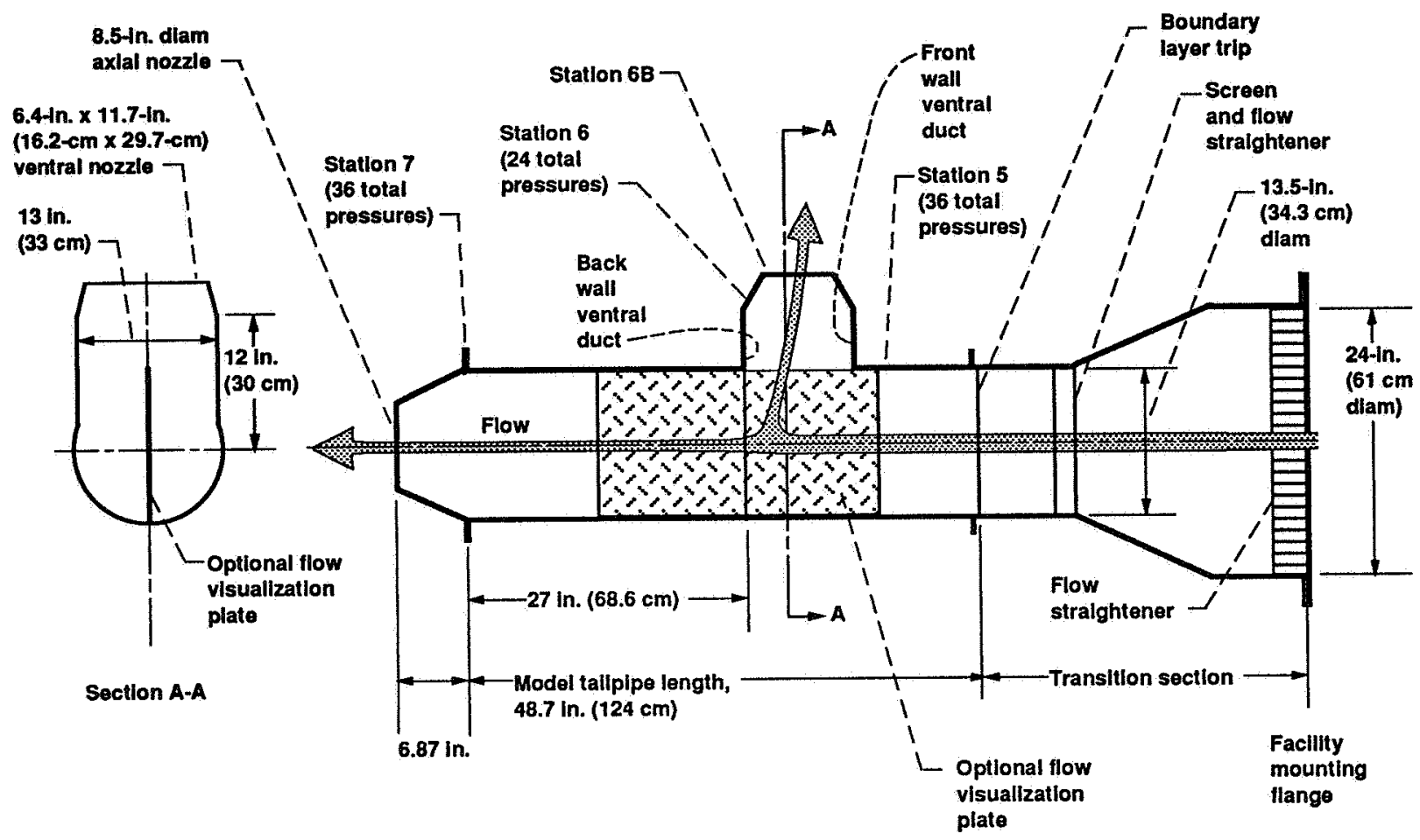

Figure 4.-Ventral and axial nozzle configuration schematic.

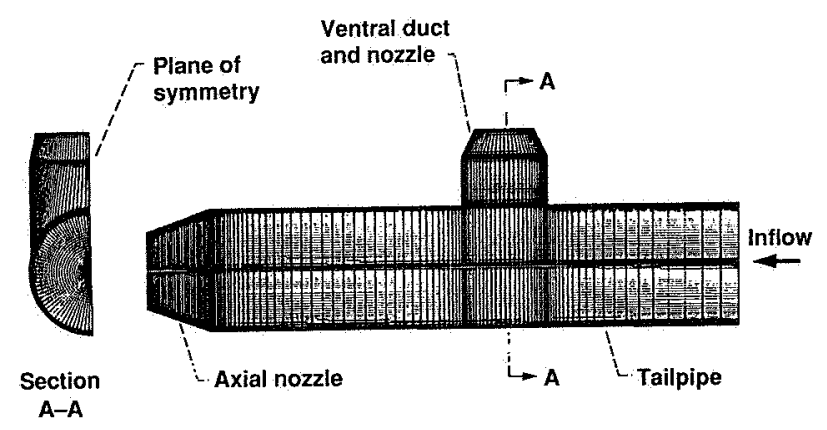

Figure 5.-Ventral and axial nozzle configuration grid, side view and section view.

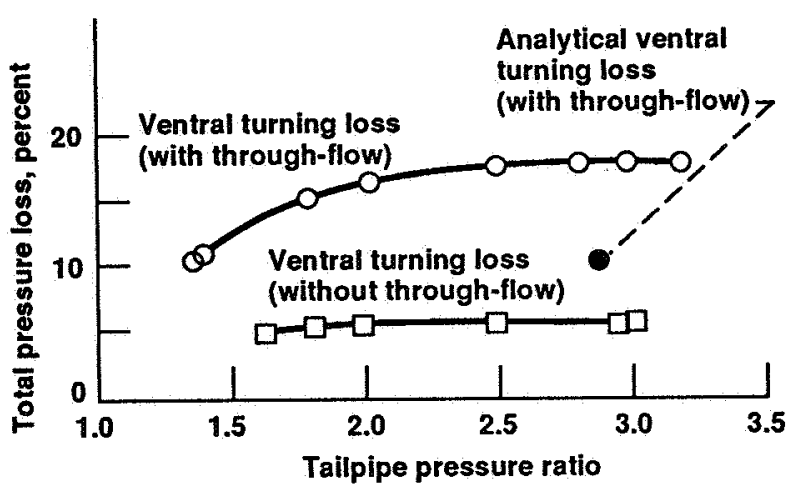

Figure 6.-System total pressure losses. $\left(\left(P_{T 5}-P_{T 6}\right) / P_{T 5}\right)$. 


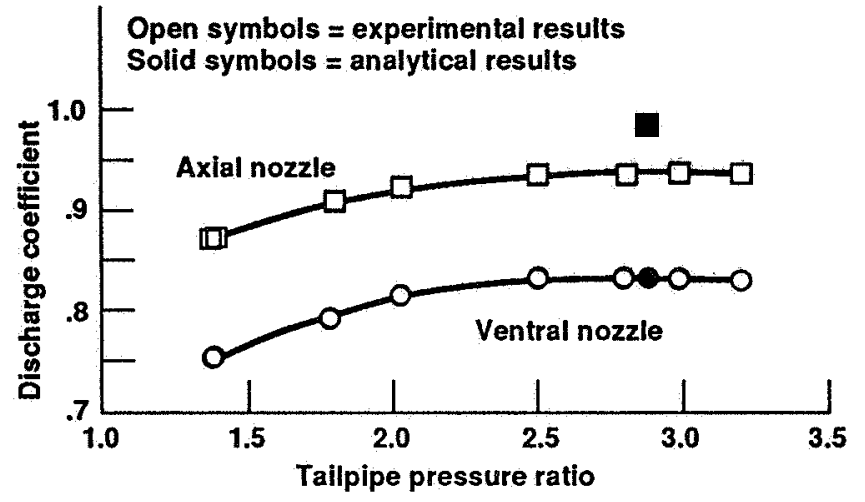

Figure 7-Discharge coefficient.

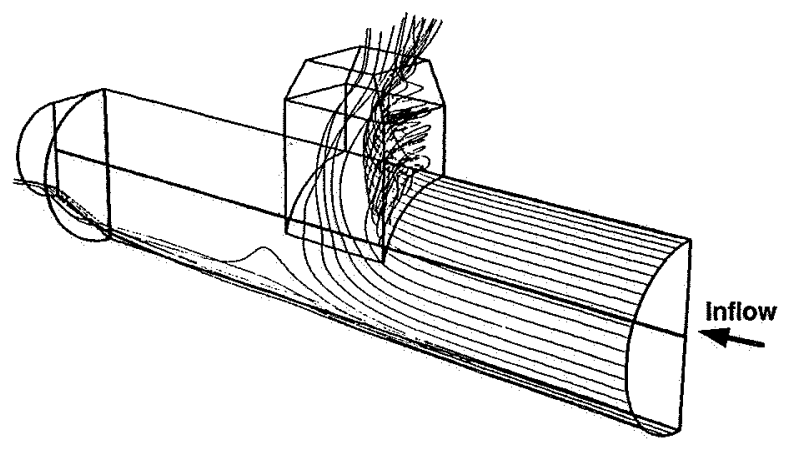

Figure 9.-Analytical particle traces in the boundary layer

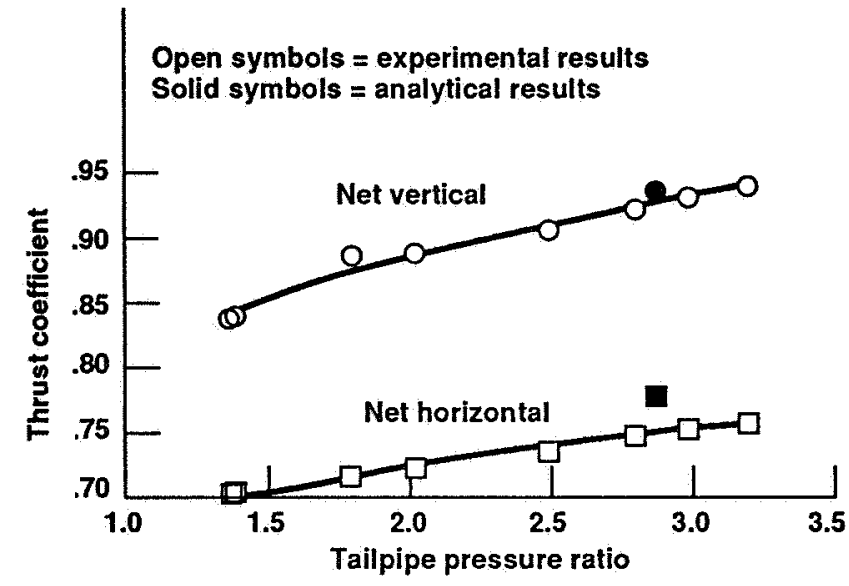

Figure 8.-Thrust coefficient.

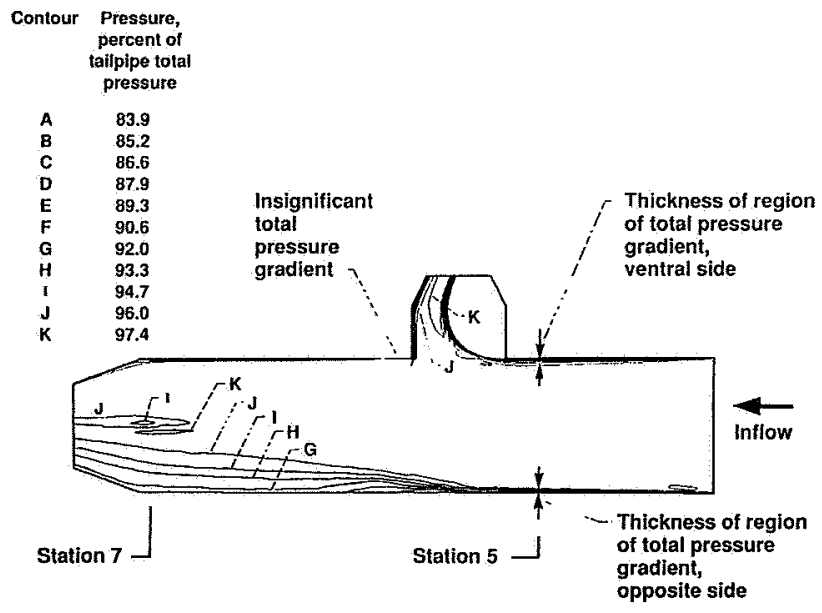

Figure 10.--Total pressure distributions àlong plane of symmetry. 


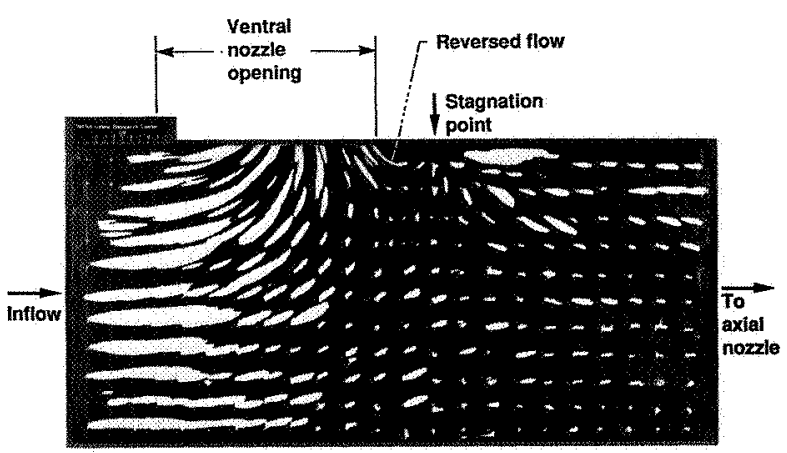

(a) Experimental results

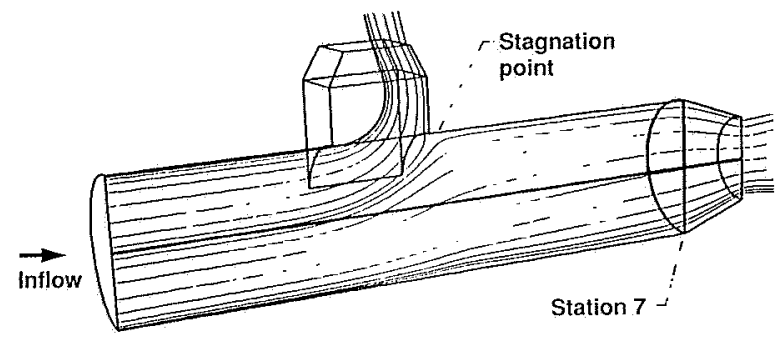

(b) Analytical particle traces

Figure 11 - Tailpipe plane-of-symmetry flow visualization.

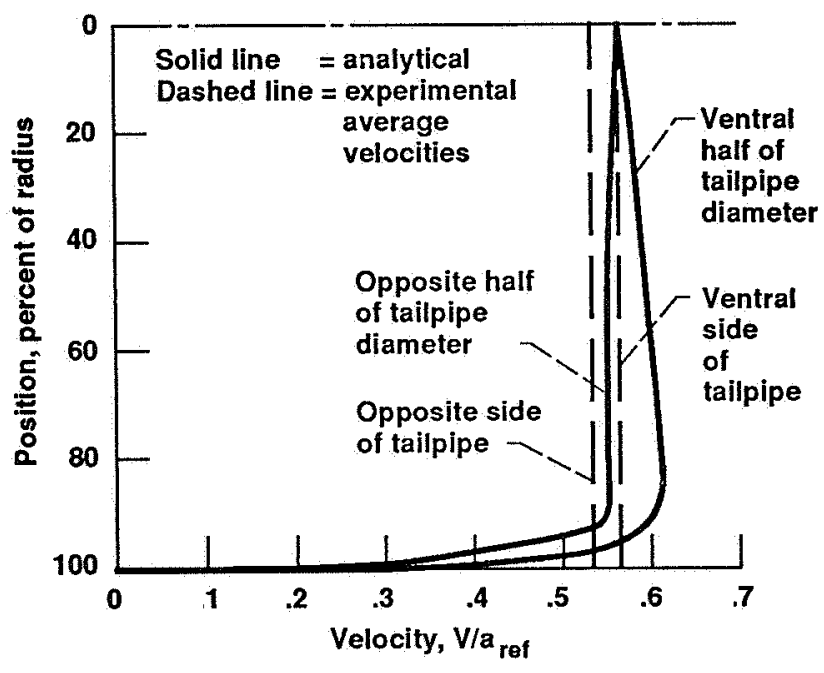

$\left(a_{\text {ref }}=\right.$ speed of sound at sea level $=1116.4 \mathrm{tt} / \mathrm{sec}$ )

Figure 12.-Analytical velocity profiles at Station 5 . 


\section{ORIGINAL PAGE \\ BLACK AND WHITE PHOTOGRAPH}

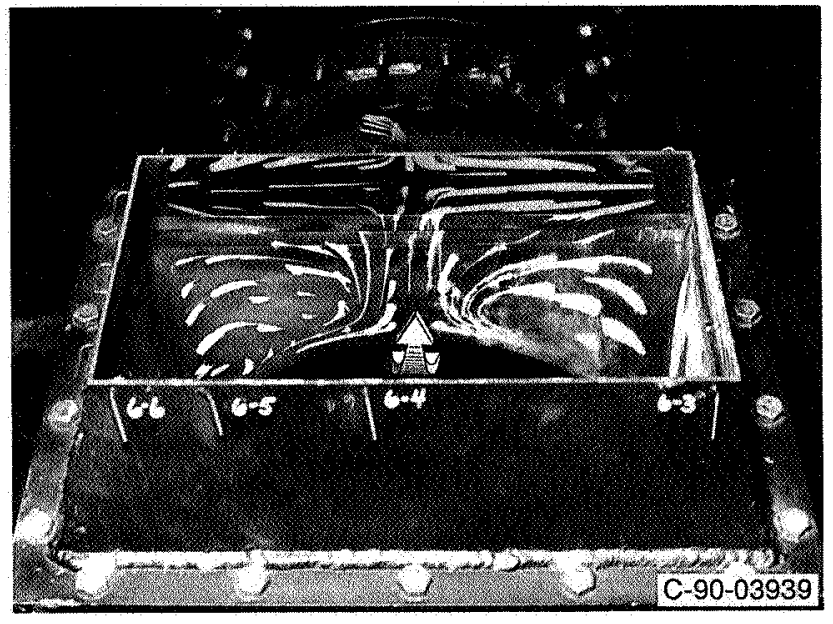

(a) Experimental results.

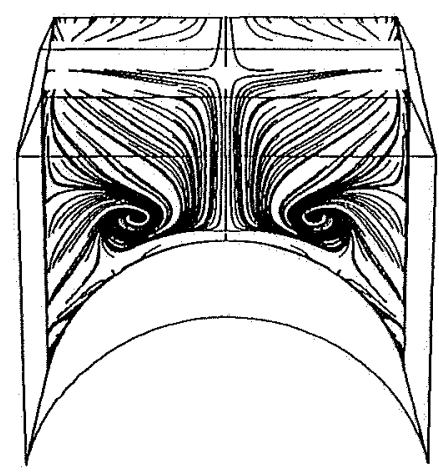

(b) Analytical results.

Figure 13.-Flow visualization on ventral duct front wall

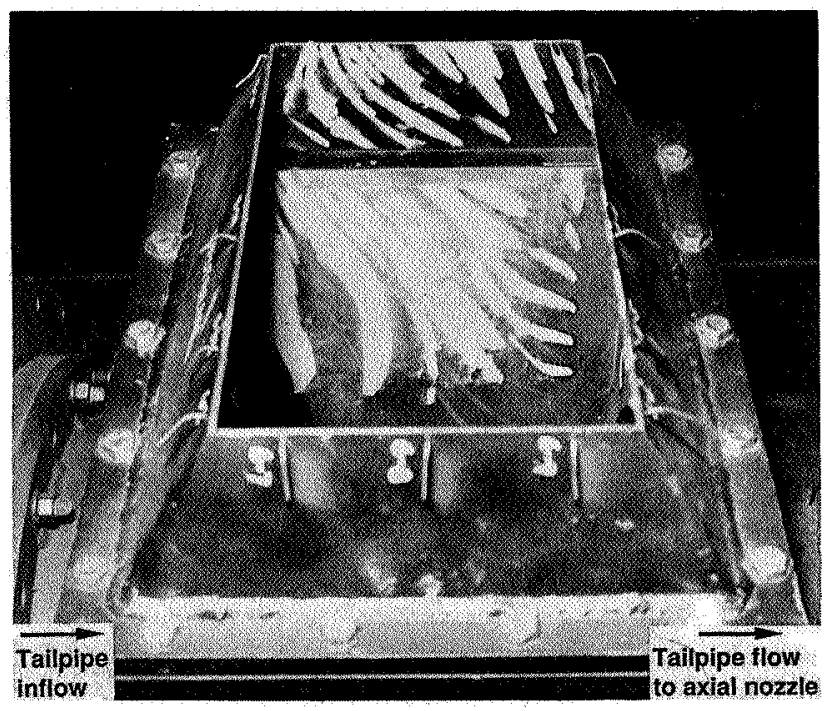

(a) Experimental results.

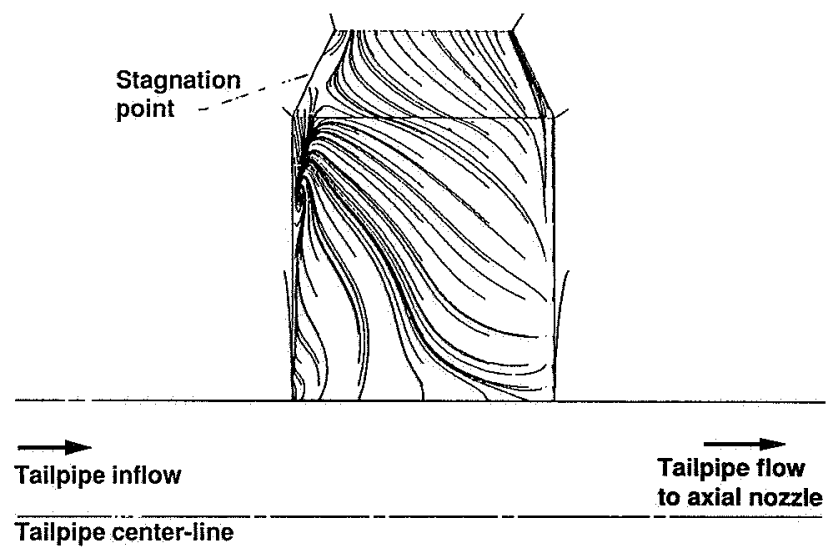

(b) Analytical results.

Figure 14.-Flow visualization on ventral duct side wall. 


\author{
ORIGINAL PAGE \\ BLACK AND WHITE PHOTOGRAPH
}

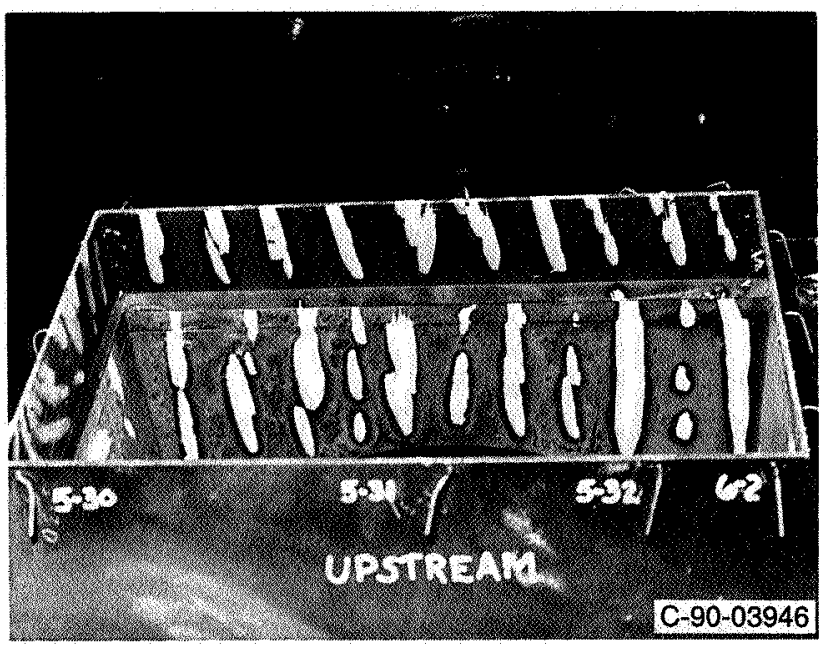

(a) Experimental results.

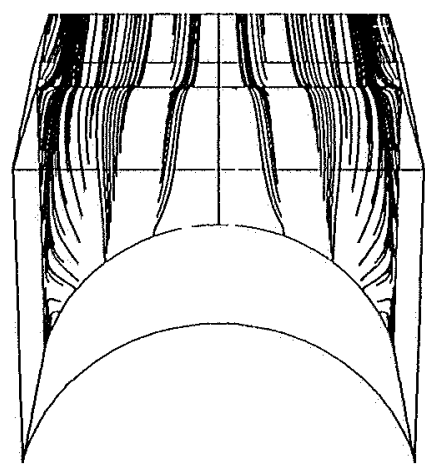

(b) Analytical results.

Figure 15.-Flow visualization on ventral duct back wall.

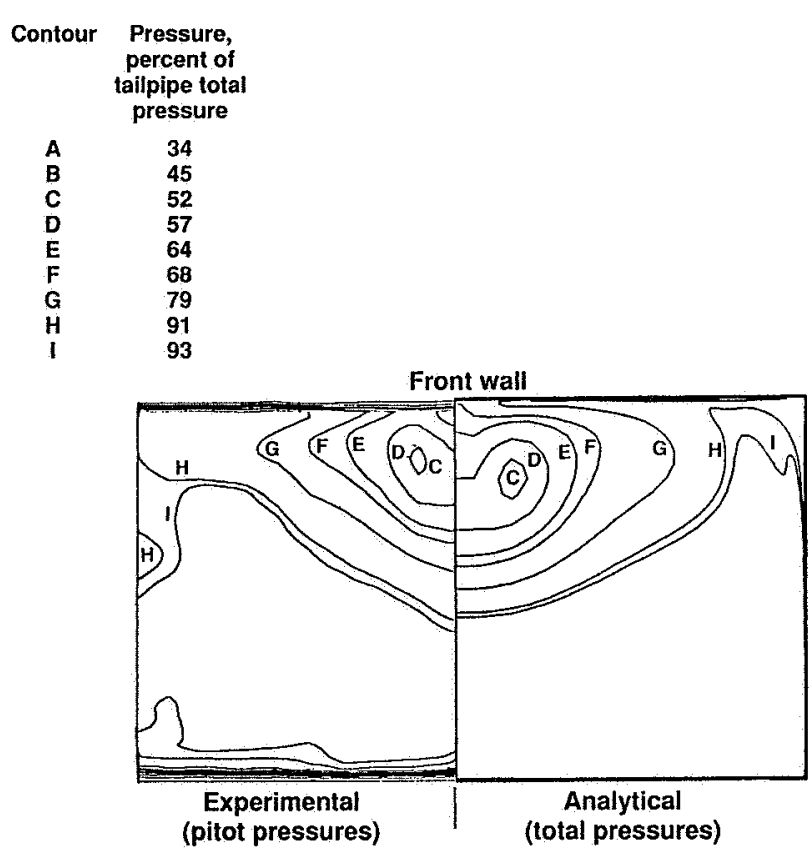

Figure 16.-Pressure contours of ventral nozzle exit plane. 


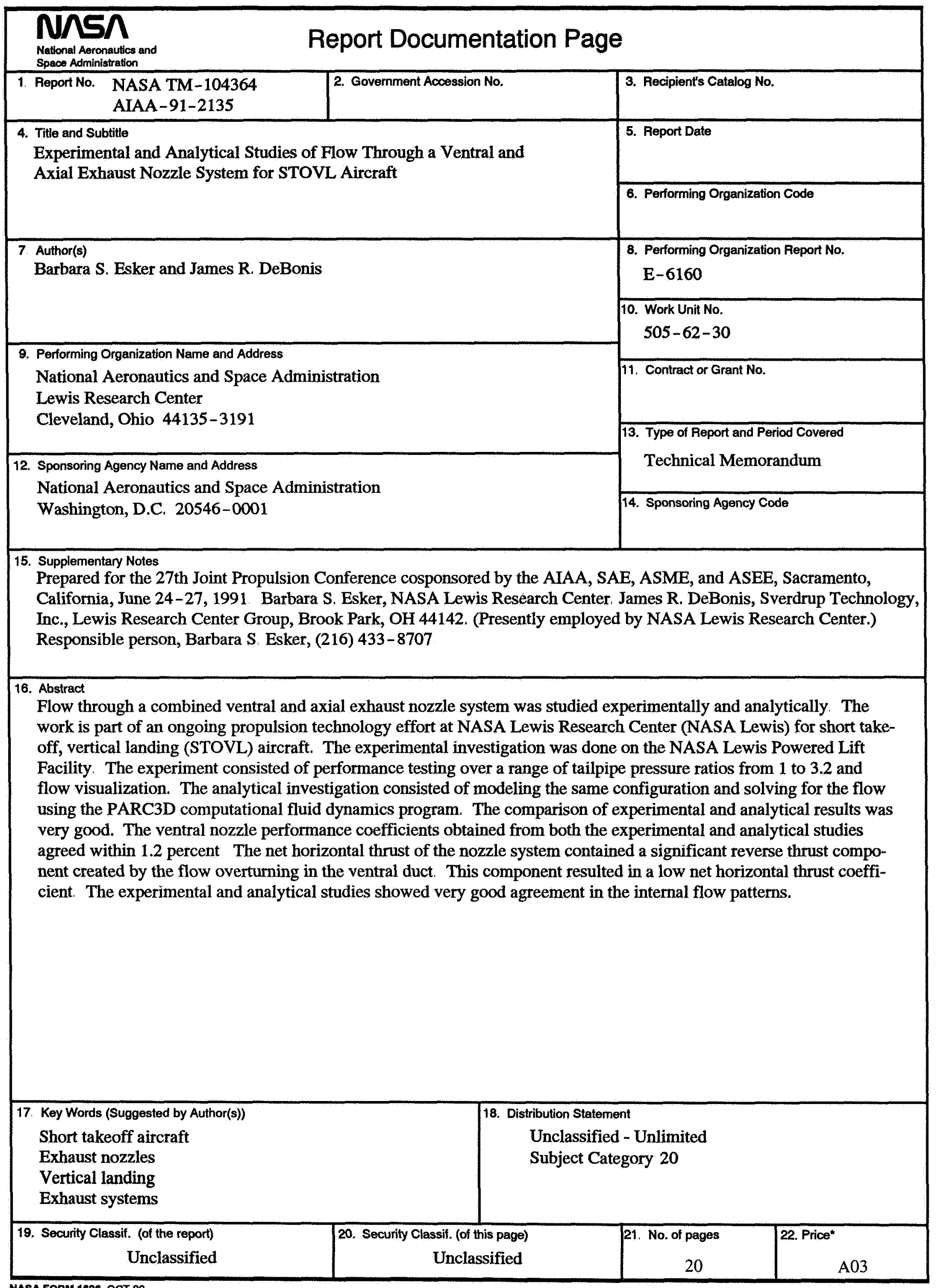

